\title{
Volatile Flavor Compounds of Matsutake-Tricholomam atsutake (ITo et IMAI) SING.-
}

\author{
Izumi Yajima, Tetsuya Yanai, Mikio NaKamura, \\ Hidemasa SaKakibara and Kazuo HaYaSHI \\ Kawasaki Research Laboratories, T. Hasegawa Co., 335 Karyiyado, \\ Kawasaki 210, Japan
}

Received June 3, 1980

\begin{abstract}
Volatile flavor compounds in the headspace vapors of fresh Matsutake were absorbed on Porapak Q in a column, then flushed out by heating the column and collected in a cold trap. They were analyzed directly by gas chromatography and gas chromatography-mass spectrometry. The aroma concentrate obtained by simultaneous distillation-extraction with a Likens and Nickerson Type apparatus was also analyzed. By both methods 59 compounds were identified and five were tentatively identified. Sixty of these compounds were identified here for the first time.
\end{abstract}

Fungi have been used since ancient times as foods and medicinal herbs. Of them, Matsutake [Tricholoma matsutake (ITo et IMAI) SING.] was considered as most pleasant and appetizing in aroma/flavor, having become for the Japanese a seasonal must in a variety of dishes. Despite being thus prized and in demand, of late, production has drastically decreased; the native Matsutake becoming scarce, expensive and difficult to obtain and hence indicating it to be a very interesting flavor for reconstitution.

In previous years, Murahashi ${ }^{1 \sim 3)}$ and Iwade $^{4,5)}$ established the existence of flavor components of 1-octen-3-ol, methyl cinnamate and several kinds of volatile aliphatic carboxylic acids in Matsutake but these being hardly enough to obtain the well balanced Matsutake flavor on mixing.

In the meantime, Takagi et al. ${ }^{6}$ have analyzed the Matsutake flavor by gas chromatography (GC), determining it to be complicated and indicating the existence of many unknown components.

We conducted analysis to identify these components which were thought to be important in the over-all flavor effect though only in trace quantities.

\section{MATERIALS AND METHODS}

Materials. Fresh Matsutake grown in the Kyoto area of Japan were used.

Methods

1) Analysis of headspace vapors containing volatile flavor compounds of Matsutake. Five hundred grams of fresh Matsutake were chopped up and placed in a 5 liter-round-bottomed flask to which was attached a column packed with Porapak $\mathrm{Q}$ as shown in Fig. 1. The flask was warmed to and maintained at $50^{\circ} \mathrm{C}$.

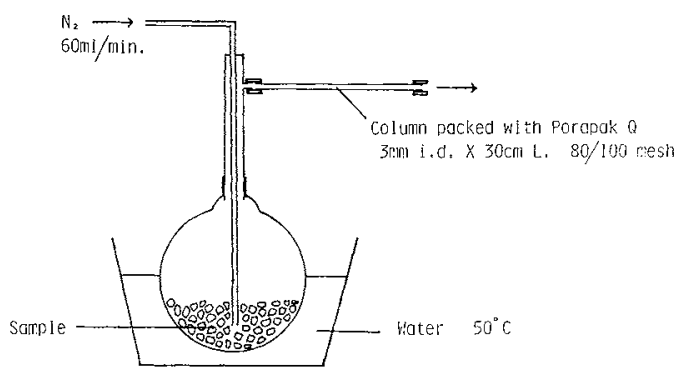

Fig. 1. Apparatus for Collecting Headspace Vapors.

Nitrogen gas was passed through the Matsutake mass at $60 \mathrm{ml} / \mathrm{min}$ for $20 \mathrm{~min}$, resulting in the rising of the volatile flavor compounds in the headspace vapors which were, in turn, drawn through the column and absorbed on the Porapak Q. After the column was detached, the moisture on the Porapak $Q$ was exhausted by injecting $\mathrm{N}_{2}$ gas at $60 \mathrm{ml} / \mathrm{min}$ for $10 \mathrm{~min}$. The column was then heated and maintained at $100^{\circ} \mathrm{C}$ after being connected to a " $U$ "-shaped glass syringe $(0.5 \mathrm{~mm}$ i.d. $\times 10 \mathrm{~cm}$ total length). Nitrogen gas was again passed through the column at $60 \mathrm{ml} / \mathrm{min}$ for $10 \mathrm{~min}$; 


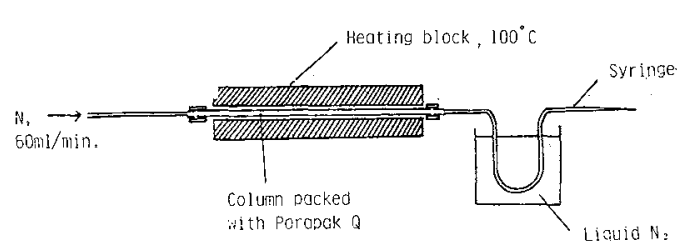

Fig. 2. Apparatus for Flushing Out Flavor Compounds.

flushing out the flavor compounds which were collected in the syringe which was cooled in liq. nitrogen as shown in Fig. 2.

The collected flavor compounds, having a pleasant and characteristic fresh but slightly musty Matsutake odor, were directly analyzed by $\mathrm{GC}$ and gas chromatography-mass spectrometry (GC-MS).

2) Analysis of aroma concentrate by simultaneous distillation-extraction. A Likens and Nickerson type apparatus ${ }^{7)}$ as shown in Fig. 3 was used. A mixture of $1 \mathrm{~kg}$ of finely chopped fresh Matsutake and $2 \mathrm{~kg}$ of water was placed in the 5 liter-round-bottomed flask, and $30 \mathrm{ml}$ of diethyl ether was placed in the $50 \mathrm{ml}-$ round-bottomed flask. Both flasks were brought to boiling and the volatile flavor compounds were simultaneously steam distilled and extracted with diethyl ether for one hour.

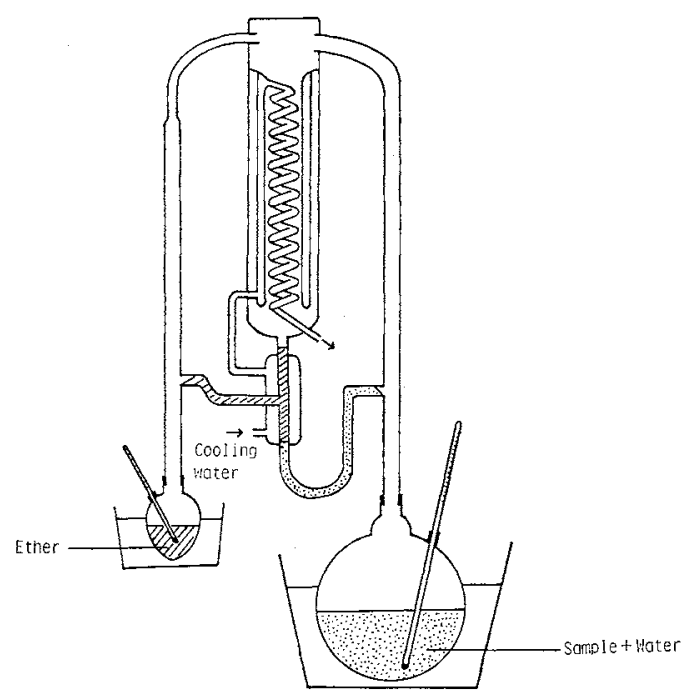

FIG. 3. Simultaneous Distillation-extraction Apparatus.

This process was repeated three times and the resulting diethyl ether extraction solution batches were combined and concentrated, giving $158 \mathrm{mg}$ of aroma concentrate which was found to have an appetizing boiled Matsutake-like aroma. This was analyzed by GC and GC-MS.
3) GC conditions. A Hitachi Model 163 gas chromatograph with a flame ionization detector (FID) and a $0.28 \mathrm{~mm}$ i.d. $\times 50 \mathrm{~m}$ glass SCOT column coated with PEG $20 \mathrm{M}$ was used. The column temperature was programmed from 70 to $190^{\circ} \mathrm{C}$ at $2^{\circ} \mathrm{C} / \mathrm{min}$. Injection port and detector temperatures were $250^{\circ} \mathrm{C}$. Nitrogen gas was used as a carrier gas at a flow rate of $1 \mathrm{ml} / \mathrm{min}$.

4) Preparative GC. Quantitatively minor compounds in the aroma concentrate were separated from major compounds by preparative GC. A Hitachi Model 163 gas chromatograph equipped with an effluent splitter was used. The separation was done by adjusting the splitter so that the effiuent was passed through at a ratio of 1 to 50 portions to the FID circuit and the exit port where a Teflon tube cooled with crushed Dry-Ice, as per Teranishi's method, ${ }^{8)}$ was placed. The tube was connected to the exit port to catch the compounds corresponding to the minor peaks and disconnected to exhaust the compounds corresponding to the major peaks into the air. Other conditions were as follows: column, $3 \mathrm{~mm}$ i.d. $\times 4 \mathrm{~m}$ glass column packed with $10 \%$ PEG $20 \mathrm{M}$ on Celite 545 SK 80/100; injection port and detector temperatures, $250^{\circ} \mathrm{C}$; column temperature, programmed from 70 to $190^{\circ} \mathrm{C}$ at $2^{\circ} \mathrm{C} / \mathrm{min}$; carrier gas flow $\left(\mathrm{N}_{2}\right), 20 \mathrm{ml} /$ min.

5) GC-MS conditions. A Hitachi Model RMU6MG mass spectrometer was used. The GC column conditions were the same as described above for the GC. Other operating parameters were as follows; column temperature, programmed from 60 to $200^{\circ} \mathrm{C}$ at $2^{\circ} \mathrm{C}$ / min; carrier gas, helium; ionizing voltage, $70 \mathrm{eV}$; accelerating voltage, $3200 \mathrm{~V}$; ion source temperature, $200^{\circ} \mathrm{C}$

\section{RESULTS AND DISCUSSION}

A gas chromatogram of headspace vapors of Matsutake is shown in Fig. 4, indicating the presence of 78 compounds, of which 22 were identified and 2 were tentatively identified by comparing and matching the mass spectra and $\mathrm{GC}$ retention times of the unknown compounds with those of authentic compounds. Table I lists the identified compounds in the headspace vapors of Matsutake. As can be seen from this table, many $\mathrm{C}_{8}$-aliphatic oxygenated compounds, similar in chemical structure to each other, were found unexpectedly in the headspace vapors of Matsutake. These compounds were thought to be major contributors to the Matsutake aroma because of their having low threshold values and their specific 


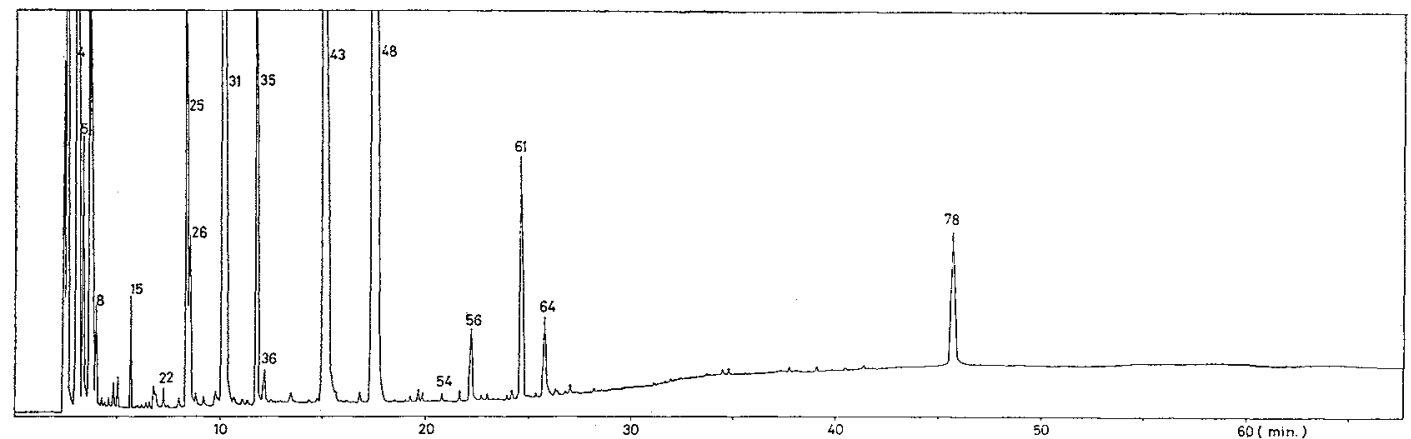

FrG. 4. Gas Chromatogram of Headspace Vapors of Matsutake.

TABle I. IDENTIFIEd Flavor Compounds from Headspace Vapors of Matsutake

\begin{tabular}{|c|c|c|c|}
\hline $\begin{array}{l}\text { Peak } \\
\text { No. }\end{array}$ & & $\begin{array}{l}\text { Peak } \\
\text { No. }\end{array}$ & \\
\hline 4 & 2-Propanol & 35 & 1-Octen-3-one \\
\hline 13 & $\alpha$-Pinene & 40 & $n$-Hexanol \\
\hline 15 & n-Hexanal & 43 & 3-Octanol \\
\hline 19 & $n$-Butanol & 47 & 2-Octenal ${ }^{a}$ \\
\hline 22 & 2-Heptanone & 48 & 1-Octen-3-ol ${ }^{b}$ \\
\hline 24 & Methyl hexanoate & 54 & Benzaldehyde \\
\hline 25 & 3-Methylbutanol & 55 & 2-Nonenal ${ }^{\alpha}$ \\
\hline 26 & Limonene & 56 & n-Octanol \\
\hline 28 & 2-Pentylfuran & 61 & $c i s-2-$ Octenol ${ }^{b}$ \\
\hline 29 & $n$-Pentanol & 64 & Phenylacetaldehyde \\
\hline 31 & 3-Octanone & 78 & Methyl trans- \\
\hline 33 & $p$-Cymene & & cinnamate $^{b}$ \\
\hline
\end{tabular}

organoleptic properties. For instance, components 3-octanone, 1-octen-3-one, and 1octen-3-ol have low threshold values ${ }^{9)}$ of 0.5 $\mathrm{ppm}, \quad 0.025 \mathrm{ppb}$ and $0.2 \mathrm{ppm}$, respectively; being, therefore, quite effective in flavor contribution despite being in trace quantities.

On the other hand, as to organoleptic properties, 1-octen-3-ol is known to be very important for the Matsutake aroma on account of having elements of Matsutake aroma. 1octen-3-one was found to have the same characteristics as this 1-octen-3-ol but was somewhat more oily.

These $\mathrm{C}_{8}$-aliphatic oxygenated compounds thus identified, including 1-octen-3-ol and 1octen-3-one, are thought to be the characteristic musty odors of all kinds of fresh mushrooms, because of their earthy to woody odors.
The 1-octen-3-one described above has previously been reported by Picardi ${ }^{10}$ to not exist in fresh mushrooms (Agaricus bisporus) but in cooked mushrooms. However, in this study, having been found in fresh Matsutake, 1-octen-3-one was seen as being possibly formed by oxidation of 1-octen-3-ol either during the process of flushing flavor compounds from the column packed with Porapak $Q$ with heating at $100^{\circ} \mathrm{C}$ or during the heating in $\mathrm{GC}$ analysis in our experiments but further clarification is necessary.

Figure 5 shows a gas chromatogram of the aroma concentrate. Major components were 3-octanone, 1-octen-3-one, 3-octanol, 1octanol, cis-2-octenol and methyl trans-cinnamate, all being, with the exception of methyl trans-cinnamate, identical to the $\mathrm{C}_{8}$-aliphatic oxygenated compounds found in the headspace vapors of Matsutake.

These major compounds constituted quantitatively over $90 \%$ of all of the compounds appearing in the gas chromatogram. Since it was difficult to identify the remaining minor compounds, preparative GC was used to separate them from the major compounds described in the preparative GC experiment.

The Teffon tube was connected to the exit port of the gas chromatograph to catch the compounds corresponding to minor peaks but was disconnected to exhaust the compounds corresponding to major peaks such as 1-octen-3-ol and methyl trans-cinnamate into the air. As a result, the aroma concentrate, from which the greater part of 1-octen-3-ol and methyl trans-cinnamate had been elimi- 


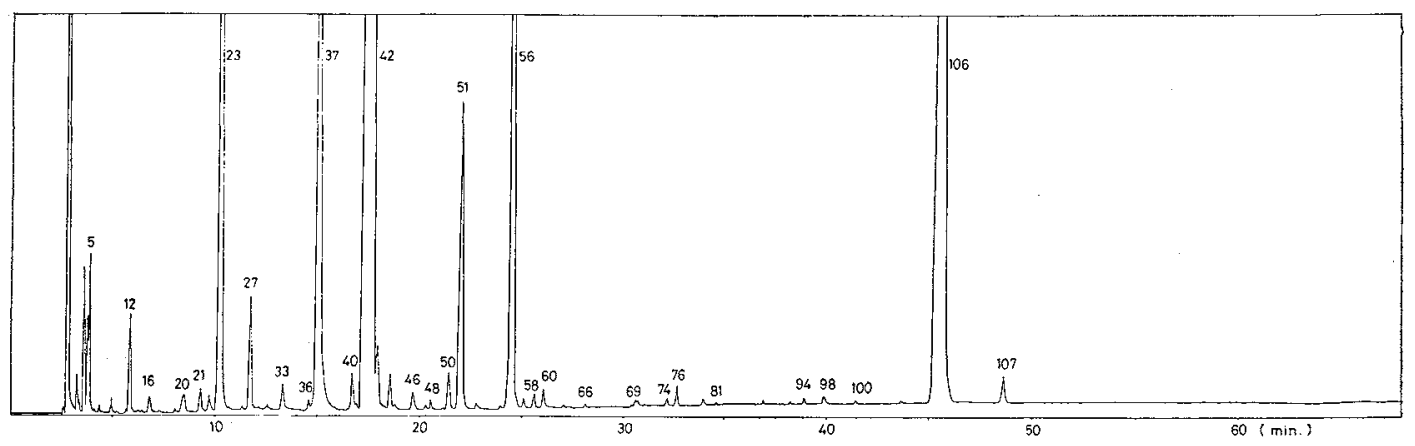

Fig. 5. Gas Chromatogram of Aroma Concentrate from Matsutake.

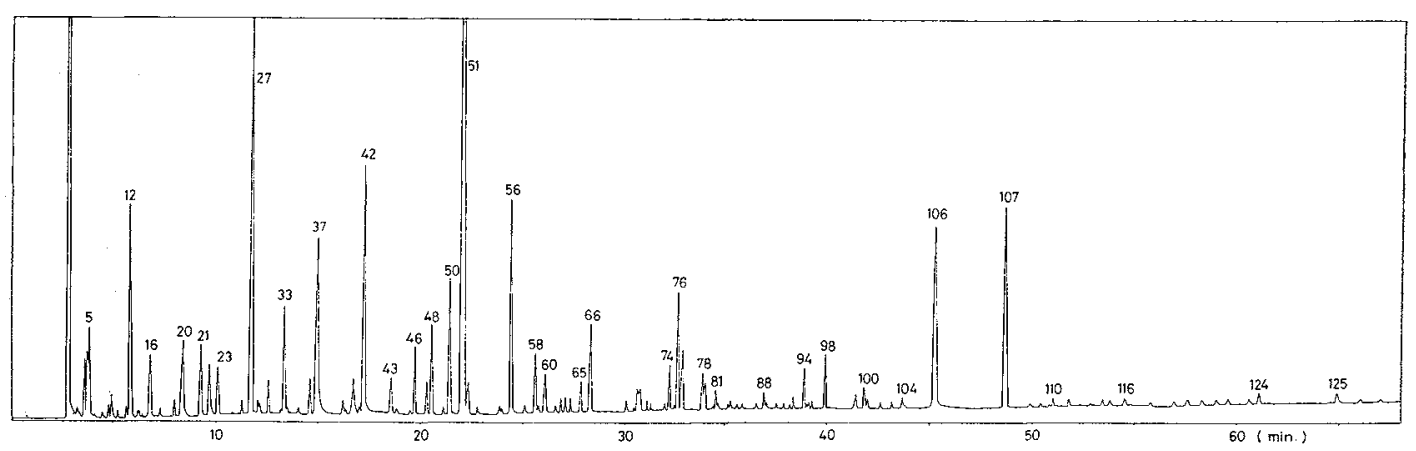

Fig. 6. Gas Chromatogram of Aroma Concentrate without Most of the 1-Octen-3-ol and Methyl trans-Cinnamate.

nated, was obtained.

Figure 6 shows a gas chromatogram of the aroma concentrate without most of the 1octen-3-ol and methyl trans-cinnamate. One hundred and twenty-seven compounds are seen in this chromatogram, of which 57 were identified and five were tentatively identified. Of the identified compounds, 58 were newly found as aroma substances of Matsutake.

Table II lists the compounds identified from both aroma concentrates obtained from Matsutake.

Methyl cinnamate, which has a pleasant, sweet Matsutake-like aroma, has also been found to be a very significant flavor compound.

Of the identified $\mathrm{C}_{8}$-aliphatic oxygenated compounds, 3-octanol, 3-octanone, 1-octen-3one, 1-octen-3-ol, and cis-2-octen-1-ol have previously been found in mushrooms (Agaricus bisporus). ${ }^{10 \sim 12)}$ Excepting 1-octen-3-ol and cis-2-octenol, all of these were identified, here, in Matsutake for the first time.
TAble II. Identified Flavor Compounds from Aroma Concentrate of Matsutake

\begin{tabular}{|c|c|c|c|}
\hline Peak No & compound & GC Rt. & GC-MS \\
\hline \multicolumn{4}{|c|}{ Hydrocarbons } \\
\hline $20^{\prime}$ & Limonene & + & + \\
\hline $67^{\prime}$ & Naphthalene & + & + \\
\hline 72 & $\begin{array}{l}\delta \text {-Cadinene } \\
\text { Alcohols }\end{array}$ & + & + \\
\hline 4 & 2-Propanol & + & $t$ \\
\hline 5 & Ethanol & + & + \\
\hline 16 & Butanol & + & + \\
\hline 20 & 3-Methylbutanol & + & + \\
\hline 22 & Pentanol & + & + \\
\hline 29 & 2-Heptanol & + & + \\
\hline 33 & Hexanol & $\div$ & + \\
\hline 36 & cis-3-Hexenol & + & + \\
\hline 37 & 3-Octanol & + & + \\
\hline 42 & 1-Octen-3-ol ${ }^{b}$ & + & + \\
\hline 50 & Linalool & + & + \\
\hline 51 & Octanol & + & + \\
\hline 56 & $c i s-2-O c t e n o I^{b}$ & + & + \\
\hline 60 & Furfuryl alcohol & + & + \\
\hline 63 & $\alpha$-Terpineol & + & + \\
\hline 87 & 2-Phenylethyl alcohol & + & + \\
\hline 104 & 3-Phenylpropyl alcohol & + & + \\
\hline
\end{tabular}




\begin{tabular}{|c|c|c|c|}
\hline peak No & compound & GC Rt. & GC-MS \\
\hline & Aldehydes & & \\
\hline 5 & 3-Methylbutanal & + & + \\
\hline 7 & Pentanal & + & + \\
\hline 12 & Hexanal & + & + \\
\hline 19 & Octanal & + & + \\
\hline 40 & 2-Octenal ${ }^{a}$ & & + \\
\hline 43 & Furfural & + & + \\
\hline 48 & Benzaldehyde & + & + \\
\hline $50^{\prime}$ & 2-Nonenal ${ }^{b}$ & & + \\
\hline 58 & Phenylacetaldehyde & + & + \\
\hline 65 & trans, trans, 2,4- & & \\
\hline & Nonadienal & + & + \\
\hline 76 & trans, trans, 2,4- & & \\
\hline & Decadienal & + & + \\
\hline 103 & Cinnamaldehyde & + & + \\
\hline & Ketones & & \\
\hline 18 & 2-Heptanone & + & + \\
\hline 23 & 3-Octanone & + & + \\
\hline 27 & 1-Octen-3-one & + & + \\
\hline 32 & 6-Methyl-5-heptene-2-one & + & + \\
\hline 45 & 2-Decanone & + & + \\
\hline 55 & 2-Undecanone & + & + \\
\hline 59 & Acetophenone & + & + \\
\hline & Esters & & \\
\hline 2 & Ethyl formate & + & + \\
\hline 3 & Ethyl acetate & + & + \\
\hline 6 & Ethyl propionate & + & + \\
\hline 10 & Ethyl 2-methylbutyrate & + & + \\
\hline 19 & Methyl hexanoate & + & + \\
\hline 24 & Hexyl acetate & + & + \\
\hline 30 & cis-3-Hexenyl acetate & + & + \\
\hline 46 & Methyl 2-octenoate ${ }^{a}$ & & + \\
\hline 53 & Bornyl acetate & + & + \\
\hline 66 & Benzyl acetate & + & + \\
\hline 74 & Methyl 2,4-decadienoate ${ }^{a}$ & & + \\
\hline 77 & 2-Phenylethyl acetate & + & + \\
\hline 94 & Methyl cis-cinnamate ${ }^{b}$ & + & + \\
\hline 106 & Methyl trans-cinnamate ${ }^{b}$ & + & + \\
\hline 107 & Ethyl cinnamate & + & + \\
\hline 116 & Methyl palmitate & + & + \\
\hline & Miscellaneous & & \\
\hline 18 & Pyridine & + & + \\
\hline 21 & 2-Pentylfuran & + & + \\
\hline 32 & 2-Hexylfuran ${ }^{a}$ & & + \\
\hline 41 & trans-Linalool oxide & + & + \\
\hline 44 & cis-Linalool oxide & + & + \\
\hline 125 & Coumarin & + & + \\
\hline
\end{tabular}

In cases of two peaks overlapping in Fig. 4, peak numbers are marked with superscript, '.

a Tentatively identified.

$b$ Previously identified.
As to the formation of these $\mathrm{C}_{8}$-aliphatic oxygenated compounds, it is generally believed that 1 -octen-3-ol is formed by oxidation of linoleic acid $^{13)}$ and that 1-octen-3-one is formed by oxidation of 1-octen-3-ol in cow's milk. ${ }^{14}$ )

It is thought, therefore, that the $\mathrm{C}_{8}$-aliphatic oxygenated compounds which were identified might have been formed enzymatically and chemically from linoleic acid via 1-octen3-ol or directly from linoleic acid. A change of some of these $\mathrm{C}_{8}$-aliphatic oxygenated compounds to other $\mathrm{C}_{8}$-compounds and vice versa is also seen as a possibility.

\section{REFERENCES}

1) S. Murahashi, Rikagaku Kenkyusho Iho, 15, 1186 (1934).

2) S. Murahashi, Sci. Pap. I.P.C.R., 30, 263 (1936).

3) S. Murahashi, Rikagaku Kenkyusho Iho, 16, 548 (1937).

4) I. Iwade, Nihon Ringaku Kaishi, 18, 528 (1936).

5) I. Iwade, Nihon Ringaku Kaishi, 19, 414 (1937).

6) H. Takagi, T. Kokura and K. Kadowaki, Abstracts of Papers, Annual Meeting of the Agricultural Chemical Society of Japan, Kyoto, 1976, p. 273.

7) T. H. Schultz, R. A. Flath, T. R. Mon, S. B. Eggling and R. Teranishi, J. Agric. Food. Chem., 25, 446 (1977).

8) R. Teranishi, R. A. Flath, T. R. Mon, and K. L. Stevens, J. Gas Chromatogr., 3, 206 (1965).

9) M. C. Meilgaard, "Geruch -und Geschmackstoffe," ed. by F. Drawert, Verlag Hans Carl, Nürnberg, 1975, p. 211.

10) S. M. Picardi and P. Issenberg, J. Agric. Food Chem., 21, 959 (1973).

11) D. A. Cronin and M. K. Ward, J. Sci. Food Agric., 21, 477 (1971).

12) E. Wascowicz, Bull. Acad. Pol. Sci., Ser. Sci. Biol. 22, 143 (1974).

13) G. Hoffmann, J. Am. Oil Chemists' Soc., 39, 439 (1962).

14) E. Honkanen, P. Karvonen and A. I. Virtanen, Acta Chem. Scand., 18, 612 (1964). 